\title{
Sexualidade no terceiro trimestre de gravidez
}

Alexandra Queirós, ${ }^{*}$ Pedro Conde, ${ }^{*}$ Vera Cunha, ${ }^{*}$ Paula Ambrósio, ${ }^{*}$ Filipe J. Marques, ${ }^{* *}$ Fátima Serrano***

\section{RESUMO}

Objectivos: Descrever a experiência sexual feminina no terceiro trimestre de gravidez.

Tipo de estudo: Estudo descritivo transversal.

Local: Consulta de Referência da Maternidade Dr. Alfredo da Costa - Lisboa, Portugal.

População: Amostra de conveniência de cem mulheres com gravidez de baixo risco, que não tinham restrições médicas na sua actividade sexual.

Métodos: As participantes completaram voluntariamente e em anonimato um questionário elaborado pelos autores respeitante a dados demográficos, história obstétrica, relacionamento sexual e esclarecimento/mitos sobre a sexualidade durante o último mês de gravidez.

Resultados: A maioria das grávidas refere diminuição da actividade sexual após engravidar, embora mantenha relações sexuais uma ou mais vezes por semana e coito vaginal no terceiro trimestre, sem mudanças significativas para outros tipos de comportamento.

Os factores que influenciam a redução da actividade sexual no terceiro trimestre são a diminuição do desejo, dispareunia e cansaço físico. Os mitos, crenças religiosas, nível de educação e dificuldade na informação sentida também parecem contribuir para a redução da actividade sexual. Frequentemente as grávidas indicam que o parceiro tem medo de prejudicar o bebé.

Poucas mulheres obtiveram informação através dos profissionais de saúde sobre este tópico e consideram que gostariam de ter sido mais bem esclarecidas pelos mesmos.

Conclusões: Os autores acreditam que na maioria dos casos a gravidez não provoca uma ruptura na sexualidade de um casal se esta era previamente satisfatória. No entanto, consideram importante a abordagem deste tema com a grávida por parte dos profissionais de saúde.

Palavras-chave: Sexualidade; Terceiro Trimestre da Gravidez.

\section{INTRODUÇÃO}

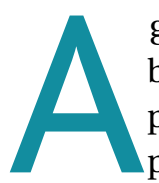
gravidez envolve um conjunto de alterações biológicas, psicológicas e sociais intensas que podem ter um impacto na sexualidade. ${ }^{1}$ Este período da vida da mulher constitui um desafio na preparação para um relacionamento triádico e, ao mesmo tempo, a continuação de um relacionamento com o companheiro, incluindo a sexualidade enquanto fonte de ligação emocional ao outro. ${ }^{2}$ Assim

*Médico do Internato Complementar de Ginecologia e Obstetrícia. Serviço de Medicina Materno-Fetal da Maternidade Dr. Alfredo da Costa, Lisboa, Portugal.

**Professor Auxiliar do Departamento de Matemática, Faculdade de Ciências e Tecnologia da Universidade Nova de Lisboa, Portugal.

***Assistente Graduada do Departamento de Obstetrícia e Ginecologia da Maternidade Dr. Alfredo da Costa e Assistente Convidada da Faculdade de Ciências Médicas de Lisboa, Portugal. a transição para a parentalidade pode iniciar ou agravar dificuldades sexuais emergentes ou pré-existentes. ${ }^{3}$

Na literatura sobre o tema noutros países e culturas, é consensual que existe uma diminuição da frequência da actividade sexual à medida que a gestação progride. ${ }^{3-17}$ Contudo são poucos os estudos publicados sobre sexualidade na gravidez na população portuguesa..$^{18-21}$

As razões mais frequentemente apontadas pelas mulheres para a diminuição da actividade sexual durante a gravidez são a fadiga, o desconforto físico (incluindo a dispareunia) e a preocupação com o bem-estar fetal. ${ }^{1,9}$ Porém, outros factores também podem condicionar a sexualidade do casal, como por exemplo: dificuldade no coito pelo abdómen proeminente da grávida, diminuição da auto-estima da mulher devido à imagem corporal, motivos culturais ou religiosos, mitos e antecedentes obstétricos (aborto, perda fetal ou infertilidade). ${ }^{4,7,9}$ 
Também são variáveis os resultados encontrados sobre as diferentes dimensões da sexualidade embora, na generalidade, sejam descritos diminuição no desejo, interesse e prazer/satisfação sexual no $1 .^{\circ}$ e $3 .^{\circ}$ trimestres. ${ }^{2,4}$ A maioria dos autores refere ainda um declínio na capacidade orgásmica da mulher durante a gravidez. ${ }^{1,2,7,9,11}$

No entanto, para a maior parte das mulheres, principalmente na gravidez, o interesse pelos aspectos não genitais do encontro sexual (intimidade, proximidade, carícias/ternura) mantém-se inalterado ou aumenta no período gravídico e é factor determinante da satisfação sexual, melhorando a sua auto-estima e a relação entre os parceiros. ${ }^{1,2}$ A estimulação vaginal torna-se menos importante no segundo e no terceiro trimestres com maior preferência por carícias não-genitais. ${ }^{1,2}$

Outras investigações mostram que as mulheres que se encontram mais satisfeitas com a qualidade do seu relacionamento conjugal são também aquelas que experimentam maior satisfação sexual durante a gravidez. ${ }^{2,11}$

Data de há mais de quarenta anos a publicação de Masters and Johnson onde foi estudada pela primeira vez a sexualidade durante a gravidez. ${ }^{4}$ Ainda assim, este assunto raramente é discutido com os médicos assistentes devido à falta de preparação dos mesmos e por sentimentos de constrangimento, apesar da maioria das grávidas desejar receber mais informação. ${ }^{7,14-18,20-23}$

O objectivo deste estudo foi descrever a experiência sexual feminina no terceiro trimestre de gravidez, contribuindo deste modo para o melhor conhecimento da experiência feminina da sexualidade durante a gravidez na população portuguesa.

\section{MÉTODOS}

Estudo descritivo transversal realizado na Consulta de Referência da Maternidade Dr. Alfredo da Costa durante os meses de Setembro e Outubro de 2007. A amostra foi de conveniência e incluiu mulheres durante o terceiro trimestre de gestação, com gravidez de baixo risco, sem restrições médicas na sua actividade sexual, que compreendiam a língua portuguesa e que sabiam ler e escrever.

Foram convidadas a participar no estudo $106 \mathrm{mu}$ lheres que frequentaram a referida consulta. Cinco mulheres recusaram participar e um questionário foi eli- minado por ter mais de $50 \%$ de respostas em branco. Foram analisados 100 questionários.

Após a consulta médica, as mulheres eram convidadas a participar no estudo de forma voluntária, liam e assinavam um consentimento informado e preenchiam a sós no gabinete médico o questionário elaborado pelos autores. Para garantir confidencialidade, após completarem o questionário, as grávidas colocavam-no numa urna.

O questionário era constituído por duas partes (em anexo). A primeira, respeitante a dados demográficos e história obstétrica, continha onze questões, 5 de resposta aberta (idade, nacionalidade, tempo de relacionamento dos parceiros, profissão e idade gestacional) e 6 de resposta fechada (etnia, habilitações literárias, estado civil, religião, filhos e abortos/perdas fetais anteriores). A segunda parte do questionário continha 10 questões referentes ao relacionamento sexual do casal (frequência das relações sexuais após engravidar e no último mês, interesse na actividade sexual, satisfação sexual, prazer sexual, orgasmo, dispareunia e tipo de práticas sexuais) e 10 questões sobre aspectos psicológicos relacionados com a sexualidade durante a gravidez (percepção de corpo menos atraente para parceiro, medo por parte dos progenitores em prejudicar o feto, cansaço físico materno, mitos populares e crenças religiosas). Por fim eram colocadas duas questões sobre o esclarecimento com os profissionais de saúde sobre o tema. Nesta segunda parte do questionário as opções de resposta eram fechadas e foram utilizados itens de Likert com cinco níveis de concordância. Para a quantificação da frequência da actividade sexual no último mês, as opções de resposta foram: duas vezes por semana ou mais, uma vez por semana, uma vez em 15 dias, uma vez por mês ou nenhuma vez. Quanto à questão que comparava a actividade sexual após engravidar com o período pré-concepcional, as opções foram: muito menor, menor, igual, maior ou muito maior. Outro tipo de opções de resposta foi utilizado conforme as questões colocadas (por exemplo: concordo completamente, concordo, desconheço, discordo e discordo completamente ou em alternativa nunca, raramente, algumas vezes, frequentemente, sempre).

Foi aplicado um pré-teste a dezassete utentes, tendo sido o questionário reformulado após a análise das respostas, reduzindo o número níveis dos itens de Likert de 8 para 5 . 
A análise dos dados foi realizada com recurso ao SPSS for Windows versão 13.0.

Utilizou-se para tratamento dos dados a estatística descritiva (média, desvio padrão, frequência e percentagem) e, como medidas de associação bivariada, o coeficiente de correlação de Spearman (medida de associação não-paramétrica entre duas variáveis pelo menos ordinais).

As respostas em branco não foram tratadas.

O estudo foi aprovado pela comissão de ética da Maternidade Dr. Alfredo da Costa.

\section{RESULTADOS}

A nossa amostra tinha idade média de 29 anos e um relacionamento conjugal com a duração média de 7 anos. Mais de metade das mulheres encontrava-se na primeira gravidez. Os resultados referentes aos dados demográficos e obstétricos estão resumidos nos Quadros I e II.

\section{Frequência do relacionamento sexual}

Quando interrogadas sobre a frequência das relações sexuais (RS) ao longo da gestação, $75 \%$ referiram um decréscimo desde o primeiro trimestre e $6 \%$ aumentou esta actividade. Relativamente apenas ao terceiro trimestre, $55 \%$ das grávidas mantiveram RS uma ou mais vezes por semana e $28 \%$ entre uma a duas vezes por mês. Dezassete por cento negou RS no último mês. Quanto à satisfação com a frequência das RS, $52 \%$ das grávidas estavam satisfeitas, $34 \%$ consideraram uma situação tolerável e 14\% estavam insatisfeitas.

\section{Interesse, satisfação, prazer e orgasmo}

A maioria das grávidas (83\%) referiu ter mantido interesse na actividade sexual e apenas $4 \%$ respondeu «sem grande interesse». Das 83 grávidas que mantiveram RS, $90 \%$ referiu actividade sexual prazerosa e $10 \%$ referiu não ter tido satisfação ou mesmo desagrado. Setenta e quatro $(90 \%)$ referiu ter alcançado o orgasmo em pelo menos metade das vezes. A frequência de orgasmo correlacionou-se de forma positiva com o tempo de relacionamento dos parceiros. ( Spearman $=0,3 ; \mathrm{p}<0,01$ ).

\section{Dispareunia e cansaço físico}

Embora a maioria das grávidas (68\%) tenha referido que nunca ou raramente tenha sentido dor durante o

\section{QUADRO I. Dados demográficos}

Idade média: 29,4 anos; (min:16 max:42; DP: 5,6)

\begin{tabular}{cc}
\hline Etnia & Percentagem de participantes \\
\hline Caucasiana & $80 \%$ \\
Africana & $17 \%$ \\
Outra & $3 \%$
\end{tabular}

Nacionalidade

Portuguesa $77 \%$

Países Africanos $\quad 10 \%$

Brasileira $\quad 11 \%$

Francesa 2\%

Religião

Católica 64\%

Nenhuma $\quad 29 \%$

Protestante $6 \%$

Outra

$1 \%$

\begin{tabular}{lr}
\hline Estado civil & \\
\hline Casada & $40 \%$ \\
União de facto & $37 \%$ \\
Solteira & $18 \%$ \\
Divorciada & $5 \%$
\end{tabular}

Escolaridade (anos)

$<5$ anos $7 \%$

5-6 anos $11 \%$

7-9 anos 28\%

10-12 anos 33\%

Ensino superior 20\%

Tempo de relacionamento entre os parceiros

Média 6,8 anos (min: 1 max: 24; DP: 4,9)

coito, cerca de um terço (32\%) referiu dispareunia em pelo menos metade das vezes.

O cansaço físico foi apontado como motivo da menor disponibilidade para as RS sempre ou quase sempre por $38 \%$ das grávidas, em cerca de metade das vezes por $22 \%$ e nunca ou raramente por $40 \%$. O maior número de filhos do casal correlacionou-se com o cansaço sentido pela grávida ( Spearman $=0,3, \mathrm{p}<0,01$ )

As correlações entre as diferentes variáveis estudadas e dispareunia e fadiga estão resumidas na Figura 1. 


\begin{tabular}{|lc|}
\hline \multicolumn{2}{|l|}{ QUADRO II. Dados obstétricos } \\
Paridade & Percentagem de participantes \\
\hline Nuliparas: & $60 \%$ \\
Multiparas: & $40 \%$ \\
\hline Número de filhos & $35 \%$ \\
\hline 1 a 2: & $5 \%$ \\
\hline 2: & \\
\hline Idade gestacional & $63 \%$ \\
\hline Média: 38 semanas (min:34 max:41 DP:1,5) \\
\hline História de aborto ou perda fetal anterior \\
\hline Nenhum & $24 \%$ \\
Espontâneos & $13 \%$ \\
\hline Provocados &
\end{tabular}

\section{Imagem corporal}

Quando questionadas se «consideravam que o seu corpo era menos atraente para o seu parceiro», 38\% referiu sentir-se com um corpo menos atraente e $35 \%$ considerou manter uma boa imagem corporal. As restantes não tinham opinião formada.

Não se encontrou correlação entre a auto-imagem e as diferentes variáveis estudadas.

\section{Comportamento sexual}

Relativamente às 83 grávidas que mantiveram RS no $3 .^{\circ}$ trimestre, a prática mais comum foi o sexo vaginal (98\%) seguido de sexo oral (39\%) e anal (7\%). Vinte e oito por cento das grávidas referiram ter praticado masturbação. Segundo as inquiridas o comportamento sexual associado a maior prazer foi o coito vaginal (81\%) seguido de masturbação (17\%) e sexo oral (13\%). (Figura 2)

\section{Medos, mitos e crenças religiosas}

Mais de metade das grávidas (61\%) afirmaram que o parceiro tem medo de prejudicar o bebé durante o acto sexual. No entanto apenas $28 \%$ referiram ter elas próprias esse receio. (Figura 3)

Quase metade das grávidas (43\%) afirmaram desconhecer se as RS poderiam provocar contracções ou sangramento e apenas $24 \%$ afirmaram acreditar nessa possibilidade. As restantes grávidas que não manifestaram estas preocupações também, na quase totalidade dos casos (85\%), não receavam a penetração.

Cinquenta e nove por cento das grávidas consideravam que algumas posições adoptadas durante o coito estavam contra-indicadas durante a gravidez. Um percentagem importante $(67 \%)$ das mulheres que receava ter hemorragia e/ ou contractilidade uterina como consequência da actividade sexual partilhava este receio.

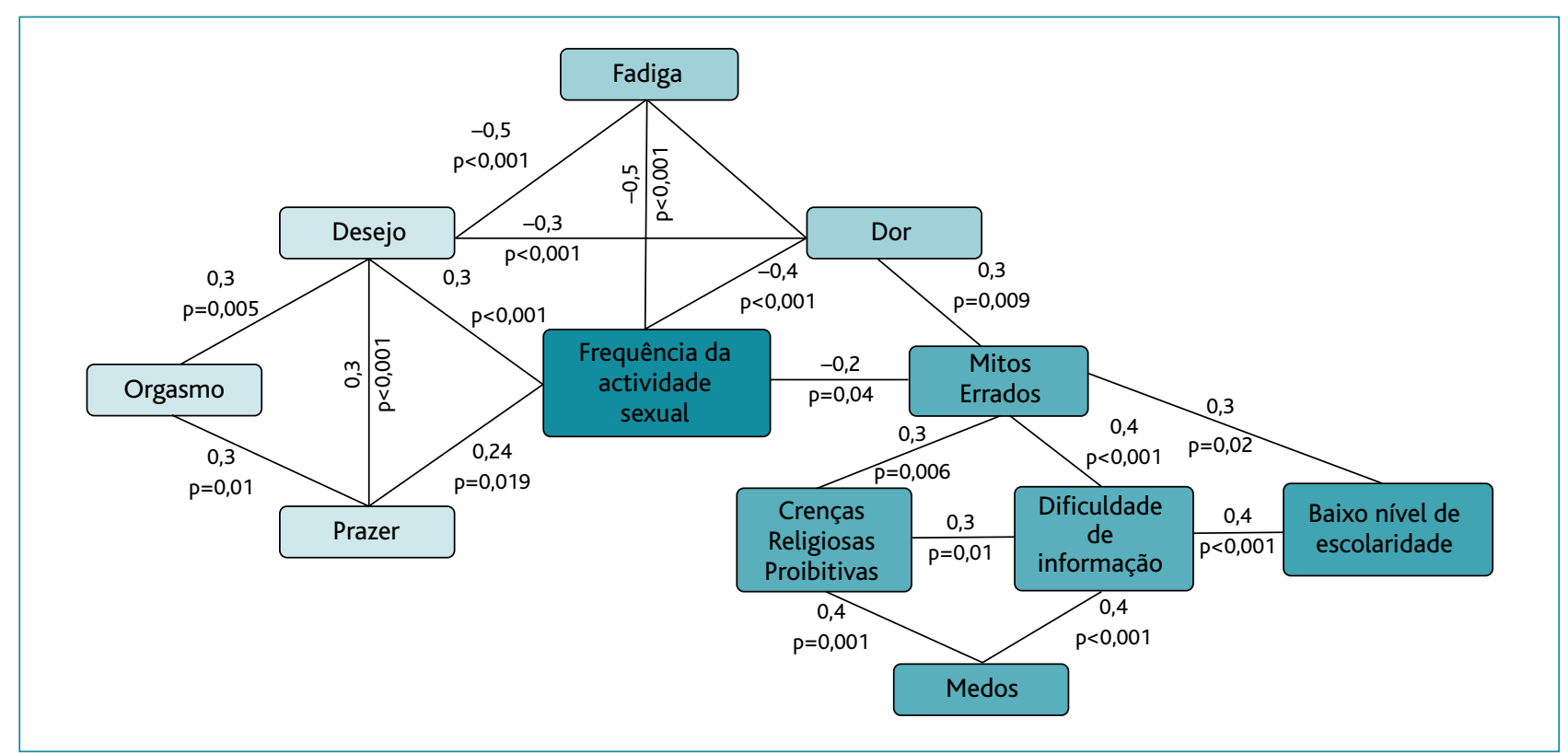

Figura 1. Correlações entre as variáveis estudadas sobre a actividade sexual no $3^{\circ} \mathrm{T}$ de gravidez. 


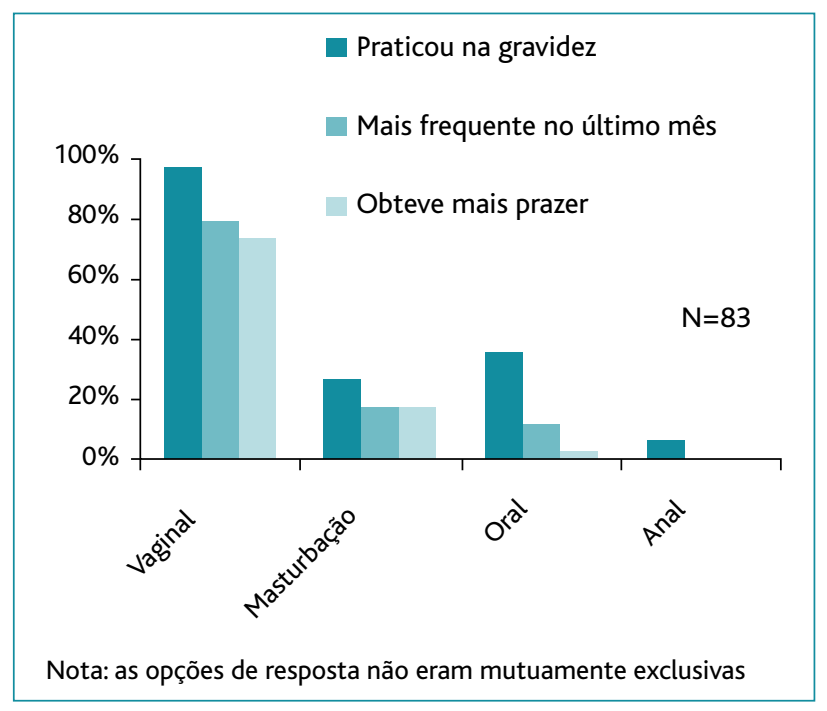

Figura 2. Práticas sexuais durante a gravidez

Com o aproximar do final da gravidez, $66 \%$ das mulheres referiam reconhecer que as relações sexuais facilitavam o início do trabalho de parto. As restantes não tinham opinião formulada.

Na nossa amostra, a maioria das grávidas (68\%) considerou que a religião não teve uma atitude proibitiva sobre a sua sexualidade. Quatro mulheres afirmaram no entanto que esta teve uma influência negativa.

As correlações bivariadas entre os medos (receio materno em magoar o feto e de contracções ou sangramento após relações sexuais), mitos (sexo sem penetração é mais seguro durante a gravidez ou algumas posições estão contra-indicadas), crenças religiosas proibitivas com as restantes variáveis estudadas estão resumidas na Figura 1.

\section{Informação pelos profissionais}

Cerca de metade das grávidas (48\%) referiu que o seu médico nunca ou raramente abordou a temática da sexualidade (Figura 4). Um terço (30\%) referiu sentir dificuldade em esclarecer as suas dúvidas com os profissionais de saúde.

Neste estudo as mulheres com melhor nível de escolaridade estavam mais bem esclarecidas e sentiamse mais confortáveis em falar sobre as questões da sexualidade com os profissionais de saúde ( Spearman = $0,4, p<0,001)$. Não foram encontradas outras associações significativas entre as restantes variáveis estuda- das, nomeadamente idade, tempo de relacionamento dos parceiros, condição marital, etnia e religião.

\section{DISCUSSÃO}

Tratou-se de uma amostra de conveniência de grávidas no terceiro trimestre o que pode implicar um viés na selecção da população, por exemplo, pelo facto da consulta de referência da Maternidade Dr. Alfredo da Costa receber grávidas de apenas algumas freguesias de Lisboa.

Embora não tenha sido estudado o comportamento sexual nos diferentes trimestres, a maior parte das grávidas referiu diminuição na frequência das RS durante todo o período da gravidez, o que está de acordo com outros estudos realizados sobre este tema..$^{5-21}$ No terceiro trimestre cerca de metade das grávidas mantiveram RS frequentes (uma ou mais vezes por semana) e apenas menos de um quinto referiu não ter tido RS no último mês.

O desejo, prazer e orgasmo parecem manter-se no último trimestre para a maioria das mulheres questionadas. A dispareunia e o cansaço físico podem justificar a diminuição da frequência e o desinteresse pela actividade sexual assim como a dificuldade em atingir o orgasmo mencionados em alguns casos.

Embora um terço das grávidas refira ter a percepção que tem um corpo pouco atraente para o parceiro, neste estudo este facto não pareceu contribuir para o decréscimo na actividade sexual do casal.

A diminuição do desejo sexual foi também relacionada na literatura com os medos da mulher relativamente à própria gestação. No terceiro trimestre esses receios encontram-se já mais especificamente relacionados com a saúde do feto, nomeadamente com a possibilidade de um parto prematuro. ${ }^{1,7-9}$ De forma surpreendente, a maioria das nossas grávidas não vivenciava estas preocupações, mas referia que esse receio existia por parte do progenitor masculino. Assim, os autores colocam a hipótese que, durante o terceiro trimestre, os maiores condicionantes para o declínio da actividade sexual serão os aspectos físicos para a gestante e os factores psicológicos para o homem. Esta preocupação com o bem-estar do feto no terceiro trimestre por parte do homem também foi encontrada noutros estudos. ${ }^{8,13}$ Teria sido importante, para melhor esclarecimento da vivência da sexualidade do casal durante a gravidez, o envolvimento do parceiro. 


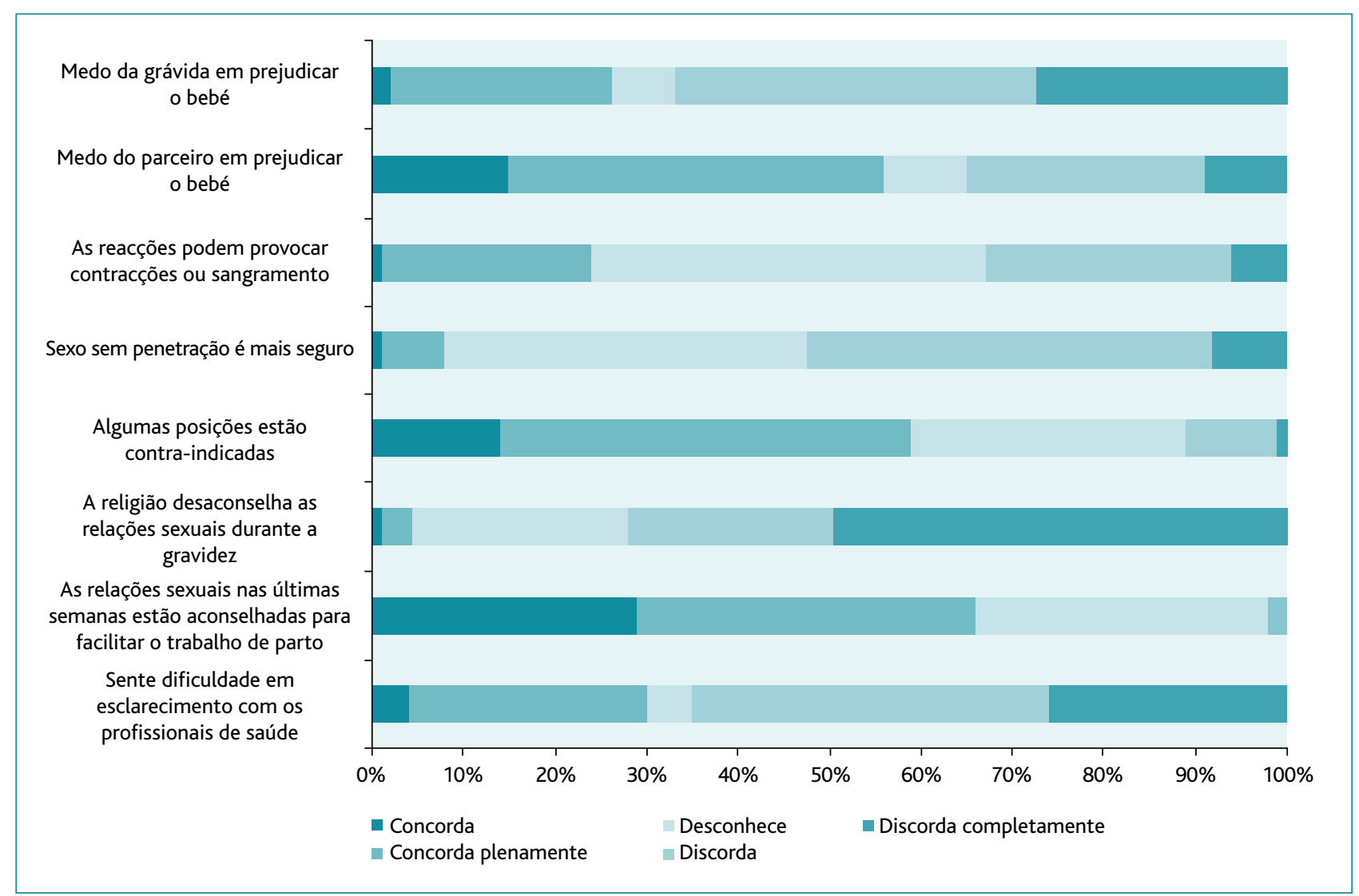

Figura 3. Esclarecimento e mitos sobre sexualidade durante a gravidez

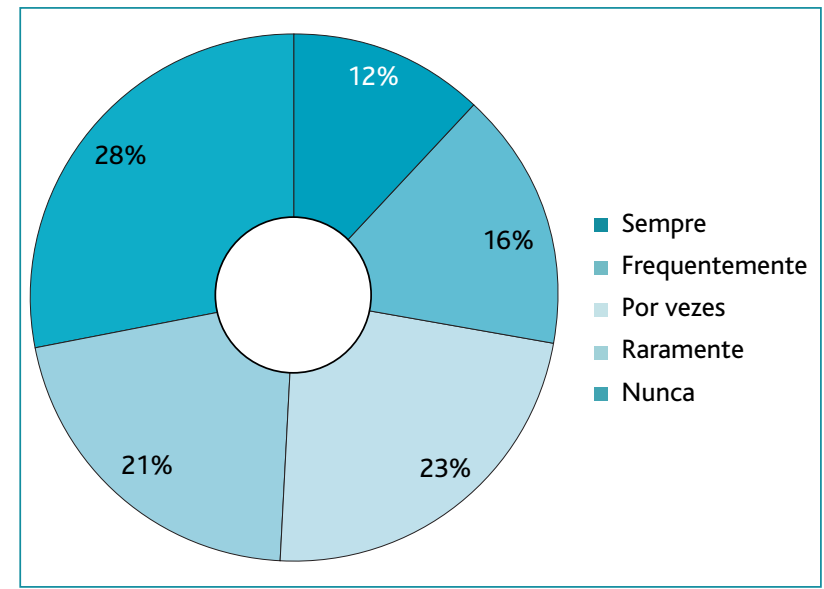

Figura 4. Frequência com que o médico abordou o assunto da sexualidade na gravidez.

Embora noutros estudos se tenha encontrado um declínio do coito vaginal com mudança preferencial para outros tipos de práticas sexuais, ${ }^{7,12}$ na nossa população o sexo vaginal manteve-se como preferencial no terceiro trimestre, o que está concordante com a pequena percentagem de mulheres que revela receio da penetração. A discriminação das posições preferidas pelas grávidas não foi questionada, o que poderia ter sido interessante avaliar. Contudo mais de metade das grávidas considera que algumas estão contra-indicadas.

Embora este estudo seja constituído por uma pequena amostra de grávidas vigiadas na região da Grande Região de Lisboa, podemos constatar que muitos profissionais de saúde ainda não abordam o tema da sexualidade durante todo o período da gravidez. A falta de preparação técnica dos mesmos e o desconhecimento da necessidade sentida pelas grávidas podem justificar estes achados. Resultados semelhantes foram também encontrados em outros estudos, 7,12,16,22,23 há mais de dez anos e no entanto parece que pouco mudou desde então. 
A actividade sexual pode prolongar-se durante toda a gestação se não houver contra-indicação médica. Beneficia o relacionamento do casal e é gratificante para a maioria das grávidas. ${ }^{12,13}$

A gravidez é um período da vida do casal em que factores biológicos, problemas médicos, crenças religiosas ou culturais e a preocupação com o bem-estar do feto podem contribuir de diferentes formas para a modificação do comportamento sexual. Assim, a sexualidade do casal pode ser condicionada por múltiplos factores, sendo difícil a sua avaliação na globalidade num único estudo. Para além da complexidade desta avaliação, juntam-se os problemas éticos e constrangimentos inerentes a qualquer estudo desta natureza, devendo por isso ser cautelosa a interpretação dos resultados. Seria interessante para o enriquecimento e validação dos relatos das grávidas a participação dos companheiros.

Em conclusão, os autores acreditam que, na maioria dos casos, a gravidez não provoca uma ruptura na sexualidade de um casal se esta era previamente satisfatória. No entanto, consideram importante a abordagem deste tema com a grávida por parte dos profissionais de saúde, dado ser um tema tão importante e ainda assim tão frequentemente esquecido.

\section{REFERÊNCIAS BIBLIOGRAFICAS}

1. Serrano F. Gravidez, parto e disfunção sexual. Arquivos da Maternidade Dr Alfredo da Costa 2005 Dez; 16 (3): 27-31.

2. Silva Al, Figueiredo B. Sexualidade na gravidez e após o parto. Psiquiatria Clínica 2005, 25 (3): 253-64.

3. Bermúdez MP, SánchezAl, Buela-Casal G. Influence of the gestation period on sexual desire. Psychology in Spain 2001, 5 (1): 14-6.

4. Masters WH, Johnson VE. Human sexual response. Londres: Churchill Livingston; 1966.

5. Adinma Jl. Sexual activity during and after pregnancy. Adv contracept 1996 Mar; 12 (1): 53-61.

6. Barclay LM, McDonald P, O'Loughlin JA. Sexuality and pregnancy: an interview study. Aust N Z J Obstet Gynaecol 1994 Feb; 34 (1): 1-7.

7. Bartellas E, Crane JM, Daley M, Bennett KA, Hutchens D. Sexuality and sexual activity in pregnancy. BJOG 2000 Aug; 107 (8): 964-8.

8. Bogren LY. Changes in sexuality in women and men during pregnancy. Arch Sex Behav 1991 Feb; 20 (1): 35-45.

9. Oruç S, Esen A, Lacin S, Adigüzel H, Uyar Y, Koyuncu F. Sexual behaviour during pregnancy. Aust N Z J Obstet Gynaecol 1999 Feb; 39 (1): 4850 .
10. Bitzer J, Alder J. Sexuality during pregnancy and postpartum period. J Sex Educ Ther 2000; 25 (1): 49-58.

11. Dejudicibus MA, McCabe MP. Psychological factors and the sexuality of pregnant and postpartum women. J Sex Res 2002 May; 39 (2): 94103.

12. Sueiro E, Gayoso P, Perdiz C, Doval JL. Sexualidad y embarazo. Aten Primaria 1998 Oct 15; 22 (6):340-6.

13. Von Sydow K. Sexuality during pregnancy and after childbirth: A metacontent analysis of 59 studies. J Psychosom Res 1999 Jul; 47 (1): 2749.

14. Kumar R, Brant HA, Robson KM. Childbearing and maternal sexuality: a prospective survey of 119 primiparae. J Psychosom Res 1981; 25 (5):373-83.

15. Solberg DA, Butler J, Wagner NN. Sexual behavior in pregnancy. N Engl J Med 1973 May 24; 288 (21): 1098-103.

16. Glazener CM. Sexual function after childbirth: women's experiences, persistent morbidity and lack of professional recognition. $\mathrm{Br}$ J Obstet Gynaecol 1997 Mar; 104 (3): 330-5.

17. Uwapusitanon W, Choobun T. Sexuality and sexual activity in pregnancy. J Med Assoc Thai 2004 Oct; 87 Suppl 3: S45-9.

18. Pauleta JR, Pereira NM, and Graça LM. Sexuality during pregnancy. J Sex Med 2010 Jan; 7 (1 Pt 1): 136-42.

19. Gomes MC. Alguns factores que influenciam o desejo sexual do casal durante a gravidez [dissertação]. Lisboa: Faculdade de Medicina da Universidade de Lisboa; 2009.

20. Lewis JA, Black JJ. Sexuality in women of childbearing age. J Perinat Educ 2006 Spring; 15 (2): 29-35.

21. Martins S, Gouveia R, Correia S, Nascimento C, Sandes AR, Figueira J, et al. Sexualidade na gravidez: influência no bebé? Mitos, atitudes e informação das mães. Rev Port Clin Geral 2007 Jul-Ago,23 (4): 369-78.

22. Heiman JR, Meston CM. Evaluating sexual dysfunction in women. Clin Obstet Gynecol 1997 Sep; 40 (3): 616-29.

23. Alteneder RR, Hartzell D. Addressing couples' sexuality concerns during the childbearing period: use of the PLISSIT model. J Obstet Gynecol Neonatal Nurs 1997 Nov-Dec; 26 (6): 651-8.

\section{CONFLITOS DE INTERESSE}

Todos os autores declaram não ter qualquer tipo de conflito de interesses relativamente ao presente manuscrito.

\section{ENDEREÇO PARA CORRESPONDÊNCIA \\ Alexandra Queirós \\ Rua Publia Hortência de Castro n. ${ }^{\circ} 7,1^{\circ} \mathrm{A}$ \\ 1500-519 Lisboa \\ E-mail: alexandrasofiaqueiros@gmail.com}

Recebido em 18/03/2011

Aceite para publicação em 04/08/2011 


\section{ABSTRACT}

\section{SEXUALITY IN THE THIRD TRIMESTER OF PREGNANCY}

Objectives: To describe the sexual activity of women in the third trimester of pregnancy.

Study Design: Cross-sectional study.

Setting: Dr. Alfredo da Costa Obstetric Hospital, Lisbon, Portugal.

Participants: One hundred pregnant women with a low risk pregnancy, without medical restrictions on their sexual activity.

Methods: An anonymous self-administered questionnaire including demographic data, information on sexual relations, and beliefs about sexuality during the last trimester of pregnancy was completed by women attending an outpatient obstetric clinic during the third trimester of their pregnancy.

Results: Most women had reduced their sexual activity during pregnancy although half of them had sexual intercourse one or more times per week and continued vaginal intercourse with no significant changes in other sexual behaviours in the third trimester.

Factors associated with a reduction in sexual activity in the third trimester were reduced desire and satisfaction, dyspareunia and fatigue. Myths, religion, level of education and lack of information from heath care providers were also associated with a reduction sexual activity. Women indicated frequently that their sexual partner was afraid of harming the baby.

A few women had information from health professionals regarding sexual activity in pregnancy and think that they should received more.

Conclusions: The authors believe that pregnancy does not disrupt sexuality in a couple with a previously satisfactory relationship. Nevertheless health professionals should discuss this topic with pregnant women more often.

Key-words: Sexuality; Pregnancy Trimester; Third.

\section{ANEXO I \\ QUESTIONÁRIO}

Pedimos a sua colaboração para um estudo sobre a sexualidade no III trimestre da gravidez. A sua colaboração é voluntária e anónima e consiste na resposta aos questionários que a seguir apresentamos. São indispensáveis alguns dados biográficos para permitir a análise dos resultados. As suas respostas serão tratadas conjuntamente com as de outras grávidas, que no seu todo nos permitirão encontrar determinados valores importantes para uma melhor compreensão do tema em estudo.

\section{Muito obrigado pela sua colaboração}

1. Idade (anos):

2. Habilitações literárias:

1) Ensino básico

2) Ciclo preparatório

3) $9 .^{\circ}$ ano ou equivalente

4) $2 .^{\circ}$ ano ou equivalente

5) Curso superior ou frequência
3. Etnia:

1) Branca

2) Negra

3) Outra (especifique):

4. Nacionalidade:

5. Profissão:

6. Estado civil:

1) Casada

2) União de facto

3) Divorciada

4) Separada

5) Viúva

6) Solteira

7. Professa alguma religião?

1) Nenhuma

2) Católica 
3) Protestante

4) Jeová

5) Judaica

6) Muçulmana

7) Outra

8. Se tem uma relação actualmente, há quanto tempo estão juntos? (anos)

9. Filhos anteriores:

1) Não

2) Sim. Quantos?

Do mesmo casamento?
1) $\mathrm{Sim}$
2) Não

\section{Abortos/Perdas fetais anteriores}

1) Não

2) Sim. Quantos?

Espontâneos

Provocados

Do mesmo casamento?
1) $\mathrm{Sim}$
2) Não

11. Tempo gravidez (semanas)

As perguntas que se seguem dizem respeito à sua vida sexual DURANTE O ÚLTIMO MÊS de gravidez, excepto indicação contrária. Assinale a sua resposta fazendo uma cruz no número que acha mais adequado.

1. Com que frequência teve relações no último mês?

1) Duas vezes por semana ou mais

2) Uma vez por semana

3) Uma vez em 15 dias

4) Uma vez por mês

5) Nenhuma vez

2. Está satisfeita com a presente frequência das suas relações sexuais?

1) Satisfeita

2) Podia ser melhor

3) Situação tolerável

4) Insatisfeita

5) Totalmente insatisfeita

3. As relações sexuais com o seu parceiro dão-lhe prazer?

1) Muito prazer

2) Prazer moderado, podiam ser melhores

3) Pouca satisfação

4) Moderadamente desagradáveis
5) Muito desagradáveis

4. Com que frequência tem orgasmo nas relações sexuais?

1) Quase sempre

2) Na maioria das vezes

3) Em cerca de metade das vezes

4) Raramente

5) Nunca

5. Sente interesse e desejo de ter relações sexuais?

1) Frequentemente, sinto forte interesse

2) Por vezes sinto bastante interesse

3) Ocasionalmente sinto ligeiro interesse

4) Sem grande interesse, nunca interessada

5) Detesto

6. Desde que engravidei a frequência com que tenho relações sexuais é:

1) Muito menor

2) Menor

3) Igual

4) Maior

5) Muito maior

7. Desde que engravidei costumo ter dor com as relações sexuais?

1) Nunca

2) Raramente

3) Em cerca de metade das vezes

4) Na maioria das vezes

5) Sempre

8. Que tipo de relações sexuais já teve na gravidez? (pode assinalar uma, várias ou todas as opções)

1) Vaginal

2) Oral

3) Anal

4) Masturbação

5) Outro

9. Qual o tipo de sexo que costuma ter mais frequentemente no último mês?

1) Vaginal

2) Oral

3) Anal

4) Masturbação

5) Outro

10. Que forma de sexo lhe deu mais prazer no ultimo mês?

1) Vaginal 
2) Oral

3) Anal

4) Masturbação

5) Outro

11. Sinto que o meu corpo é menos atraente para o meu parceiro...

1) Concordo completamente

2) Concordo

3) Não concordo nem discordo

4) Discordo

5) Discordo completamente

12. O cansaço físico na gravidez dificulta a minha disponibilidade para ter relações...

1) Nunca

2) Raramente

3) Em cerca de metade das vezes

4) Na maioria das vezes

5) Sempre

13. Tenho medo que as relações sexuais possam prejudicar o bebé...

1) Concordo completamente

2) Concordo

3) Desconheço

4) Discordo

5) Discordo completamente

14. O meu parceiro tem medo de prejudicar o bebé...

1) Concordo completamente

2) Concordo

3) Não concordo nem discordo

4) Discordo

5) Discordo completamente

15. As relações sexuais podem provocar contracções ou sangramento...

1) Concordo completamente

2) Concordo

3) Desconheço

4) Discordo

5) Discordo completamente

16. O sexo sem penetração está mais indicado (mais seguro) na gravidez...

1) Concordo completamente

2) Concordo

3) Desconheço

4) Discordo
5) Discordo completamente

17. Não se deve ter relações sexuais após saída do rolhão mucoso...

1) Concordo completamente

2) Concordo

3) Desconheço

4) Discordo

5) Discordo completamente

18. Algumas posições estão contra-indicadas (não aconselhadas) na gravidez...

1) Concordo completamente

2) Concordo

3) Desconheço

4) Discordo

5) Discordo completamente

19. A minha religião desaconselha as relações sexuais na gravidez...

1) Concordo completamente

2) Concordo

3) Desconheço

4) Discordo

5) Discordo completamente

20. As relações sexuais nas últimas semanas de gravidez estão aconselhadas para facilitar o inicio do trabalho de parto

1) Concordo completamente

2) Concordo

3) Desconheço

4) Discordo

5) Discordo completamente

21. Sinto dificuldade em falar e esclarecer as minhas dúvidas sobre sexualidade com os profissionais de saúde...

1) Concordo completamente

2) Concordo

3) Desconheço

4) Discordo

5) Discordo completamente

22. O meu médico/obstetra abordou (falou sobre) o assunto na gravidez durante as consultas...

1) Concordo completamente

2) Concordo

3) Desconheço

4) Discordo

5) Discordo completamente 